\section{HAPTIC VIRTUAL ENVIRON- MENTS FOR BLIND PEOPLE: EXPLORATORY EXPERIMENTS WITH TWO DEVICES}

\author{
G Jansson $^{1}$, H Petrie ${ }^{2}$, C Colwell ${ }^{2}$, D Kornbrot ${ }^{2}$, J Fänger ${ }^{3}$, \\ $\mathrm{H} \mathrm{König}^{3}$, K Billberger ${ }^{1}$, A Hardwick ${ }^{4}$, and S Furner ${ }^{4}$ \\ ${ }^{1}$ Uppsala University, SWEDEN \\ ${ }^{2}$ University of Hertfordshire, UK \\ ${ }^{3}$ University of Magdeburg, GERMANY \\ ${ }^{4}$ British Telecommunications plc, Research Laboratories,
} UK

\begin{abstract}
This paper is a fusion of two independent studies investigating related problems concerning the use of haptic virtual environments for blind people: a study in Sweden using a PHANToM 1.5 A and one in the U.K. using an Impulse Engine 3000. In general, the use of such devices is a most interesting option to provide blind people with information about representations of the $3 \mathrm{D}$ world, but the restriction at each moment to only one point of contact between observer and virtual object might decrease their effectiveness. The studies investigated the perception of virtual textures, the identification of virtual objects and the perception of their size and angles. Both sighted (blindfolded in one study) and blind people served as participants. It was found (1) that the PHANToM can effectively render textures in the form of sandpapers and simple 3D geometric forms and (2) that the Impulse Engine can effectively render textures consisting of grooved surfaces, as well as 3D objects, properties of which were, however, judged with some over- or underestimation. When blind and sighted participants' performance was compared differences were found that deserves further attention. In general, the haptic devices studied have demonstrated the great potential of force feedback devices in rendering relatively simple environments, in spite of the restricted ways they allow for exploring the virtual world. The results highly motivate further studies of their effectiveness, especially in more complex contexts.
\end{abstract}

\section{Introduction}

The most common function expected to be fulfilled by haptic force feedback displays is to enhance the perception of virtual reality scenes rendered by visual and/or auditory displays in medical, entertainment, tele-robotic, and military applications (Burdea, 1996). When a haptic display is considered for people with visual impairments, the introduction of $3 \mathrm{D}$ haptic information holds great promise, but the lack of visual guidance may decrease the effectiveness in utilising the haptic information, as vision and haptics normally co-operate (Heller, 1982).

The problems which arise when haptics is not guided by vision include obtaining an overview of the display and locating the relevant parts of it, as well as picking up 3D aspects of a display depicted in 2D (cf. Jansson, 1988). If overview and location of parts have to be obtained by haptics alone, very long exploration times may be needed. With respect to obtaining $3 \mathrm{D}$ aspects from $2 \mathrm{D}$ haptic depictions, it has been suggested that this is an impossible task (Révész, 1950), and in applied work with tactile pictures (for an overview, see Edman 1992), 3D aspects of pictures are not emphasised. On the other hand, there are reports indicating that perspective information may be useful for haptic perception of 3D aspects (Heller, Calcaterra, Tyler \& Burson. 1996; Holmes, Hughes \& Jansson, 1998; Kennedy, 1993). 2D cutaneous information may thus contribute to the perception of $3 \mathrm{D}$ objects, but there are many problems left for research on what conditions favour 3D percepts from cutaneous information. In addition to cutaneous information, haptic perception involves information from the position and movements of the limbs and body. The information is provided by sensors in the muscles, tendons and joints. The importance of this information was strongly emphasised in seminal papers by Katz (1925/1989) and Gibson (1962), but the relative contribution of cutaneous and movement information to haptic perception has subsequently been much discussed. Many authors state that relative motion between skin and object is the important factor, pointing to experiments where the performance is the same whether the hand or the object is moving (e.g. Lamb, 1983, Lederman, 1981, 1983). Hughes \& Jansson (1994) noted that most studies of this problem concerned texture perception and that the applicability of the equivalence of movement of observer and of object can not be generalised to other types of haptic perception without further evidence. Vega-Bermudez, Johnson and Hsiao (1991) achieved equivalence between the two kinds of movement for tactile letter recognition, but they only studied patterns smaller than the finger pad. In contrast, Jansson (1998) found significant differences between active exploration and passive reception of cutaneous information when studying larger 2D virtual geometric forms.

The problem of the relative contribution of cutaneous and movement information to haptic perception has direct relevance for the usefulness of force feedback displays for people with visual impairments. Force feedback displays emphasise information from observer movements and are much less concerned with cutaneous information. In many cases, including the ones studied here, the equipment defines only one point at a time for contact between observer and virtual object, which is much less than the cutaneous information available in natural contexts. If the movement information is sufficient this does not decrease the effectiveness of the display; but if the cutaneous information also is important, the restriction to one point does decrease it. Lederman and Klatzky (in press) 
conducted a series of experiments indicating that restriction of cutaneous information to one point substantially impaired performance. When they applied these results to the design of haptic displays, they suggested that there may be significant costs of not providing the fingertips with spatially distributed force patterns, at least for novice operators.

As discussed above, there are both pros and cons concerning the usefulness of currently available haptic force feedback displays. The general aim of the present studies, is to investigate the extent to which devices of this kind can be useful in spite of their limitations. The most positive aspect in favour of their usefulness is that they offer free exploratory movements in $3 \mathrm{D}$ space; the most negative aspect is the restricted cutaneous information. It is reasonable to assume that the outcome will vary with the complexity of the depiction. Here some relatively simple textures and 3D objects are studied.

\section{Perceived Roughness of Real and Virtual Sandpapers}

\subsection{PROBLEM}

Texture is one of the most important properties of an object and a property that haptics readily can detect (for an overview, see Loomis \& Lederman, 1986). Sandpapers have been used in many studies about texture, one reason being that the physical properties of their texture can be clearly defined and ordered. In order to study how well virtual sandpapers reproduce the texture of real sandpapers in a form that is useful for observers, the perception of the roughness of real and virtual sandpapers were compared. As exploration method may affect the result, the same method was used in both conditions, namely exploration with a stylus.

The experimental problem was thus the following: How well do blindfolded sighted observers' perception of the roughness of real and virtual sandpapers agree when they are explored with a stylus?

\subsection{HAPTIC DISPLAY}

A PHANToM 1.5A from Sensible Technologies, Inc., Cambridge, MA, USA, was used as the haptic display (see Fig. 1). It is a robot driving a two-linked arm, the tip of which is freely movable within a $19.5 \times 27 \times 37.5 \mathrm{~cm}$ workspace with a nominal position resolution of $.03 \mathrm{~mm}$, maximum exertable force of 8.5 Newtons and inertia (apparent mass at tip) of $<75 \mathrm{~g}$ according to Sensible specifications (for more details, see the web site http://www.sensable.com). The device was driven by a Scandic Computer equipped with a Pentium Pro $200 \mathrm{MHz}$ and with Windows NT Workstation 4.0.

The tip of the PHANToM arm was provided with the standard stylus, which means that the point of contact with the virtual object was at the end of this stylus. For the exploration of the real sandpapers, a stylus was constructed which was a copy of the one used by the PHANToM but with an additional $50 \mathrm{~mm}$ long and $3 \mathrm{~mm}$ thick steel tip with a pointed tip corresponding to the stylus used when collecting physical sandpaper data.

\subsection{METHOD}

\subsubsection{Participants.}

Twelve paid sighted university students (seven women and five men) with a mean age of 25 years ( $\mathrm{SD}=2.4$ years) participated. All with the exception of one man explored with their right hand.

\subsubsection{Stimuli.}

Figure 1. A PHANToM Haptic Interface (1.5A model) used with a stylus

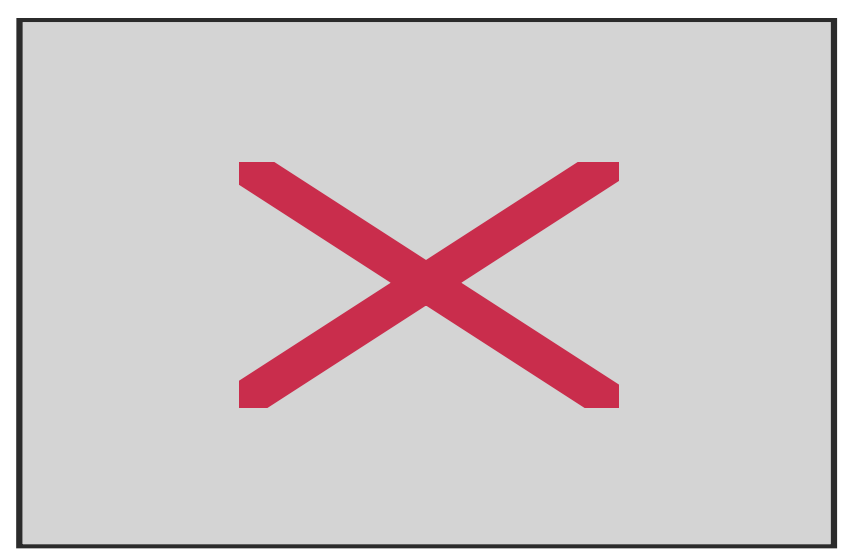

For the real sandpapers, four Norton Metalite sandpapers with 50, 80, 120 and 220 grit, respectively, were used. (For standard specifications, see http://www.wirecloth.com/howto/convert/ussueve.html.). Virtual sandpapers were presented by the PHANToM with a method developed by Green \& Salisbury (1997). The PHANToM is first used to acquire data from a sample of respective sandpapers. A vertical stylus with one end attached to the PHANToM arm and the other end resting on the horizontal sandpaper is made to follow a trajectory in the form of a straight line at a constant speed and exerting a constant force. Lateral forces and the $\mathrm{z}$ position of the endpoint during the movement are recorded. The collected data are used to calculate the vector of $\mathrm{z}$ values and means and standard deviations of the static friction coefficients which are used for the simulation. The virtual surfaces are not exact copies of the real surfaces but the properties used in the simulation are intended to be sufficient for allowing accurate perception of the roughness of the sandpapers.

\subsubsection{Procedure}

Before using the PHANToM participants were informed about the device and safety aspects of its use (a standard head protective device common in industry was placed on the 
participant's head) and were allowed to acquaint themselves with it. They were instructed to hold the stylus as vertically as possible close to its lower end and to move it approximately in a straight line back and force applying the same constant force during the whole experiment.

Before exploring the real sandpapers the participants were instructed to hold the specially made stylus as vertically as possible and closely above the steel part of the stylus (about 5 $\mathrm{cm}$ from the pointed tip) and keep the hand such that it did not touch the sandpaper. The instructions about movements were the same as those for the virtual sandpapers.

When the participants were ready to start, they were asked to choose hand for the exploration, the same hand used for the whole experiment. They were equipped with eye cover and earphones playing white noise and the experiment proper began. 2.3.4 Psychophysical Method

The magnitude estimation technique (e.g. Snodgrass, Levy-Berger \& Haydon, 1985), widely accepted in studying psychophysics, was used to assess the perceived roughness of the textures. Participants were presented a standard stimulus, in half the trials the real 120 grit sandpaper, in the other half the corresponding virtual sandpaper. They were instructed to assign the number 100 to their perception of the roughness of this stimulus. The participants were then presented with the experimental textures one by one. For each presentation, they were asked to give a number which represented the perceived texture of the new presentation relative to the standard. No roughness was defined as 0 and there was no maximum limit for the number to be assigned. If the texture was perceived as twice as rough, they would give it the number 200, if it was perceived as half as rough, they would give it the number 50. Participants may find this method difficult, but for many physical stimuli it has been shown to reveal the relationships between physical parameters and perceived property.

\subsubsection{Design}

All participants took part in all the experimental conditions and the trials were arranged in four main blocks: virtual texture with virtual standard, virtual texture with real standard, real texture with virtual standard and real texture with real standard. Each main block consisted of six blocks each containing a presentation of the standard sandpaper followed by the four experimental sandpapers. All orders were randomised: for half the participants, and the reverse orders were used for the remaining participants.

\subsection{RESULTS}

Figure 2 illustrates the effects of physical roughness on perceived roughness for real and virtual sandpapers. A four way ANOVA demonstrated significant effects of roughness $\left(\mathrm{F}_{3,33}=168.95, \mathrm{p}<.001\right)$ and replication $\left(\mathrm{F}_{5,55}=3.56, \mathrm{p}\right.$ $<.01)$ and interaction between standard and replication $\left(\mathrm{F}_{5,55}=2.46, \mathrm{p}<.05\right)$, but no significant effects for stimulus type (real/virtual) $\left(\mathrm{F}_{1,11}=2.98, \mathrm{p}>.05\right)$ and standard $\left(\mathrm{F}_{1,11}\right.$ $=.11, \mathrm{p}>.05)$, nor for any other interactions.

\subsection{DISCUSSION}

The result indicates that the real and virtual sandpapers are perceived in very much the same way, at least when they are similarly explored. The simulation of these textures can thus be considered as successful. It should be noted, however, that there was a tendency at all levels of roughness of virtual sandpapers to be perceived as somewhat rougher than corresponding real sandpapers. This may mean that a significant difference would show up if the number of participants were larger, but the smallness of the difference means that such a result can not be expected to have any

Fioure 2 Perceived roughness as a function

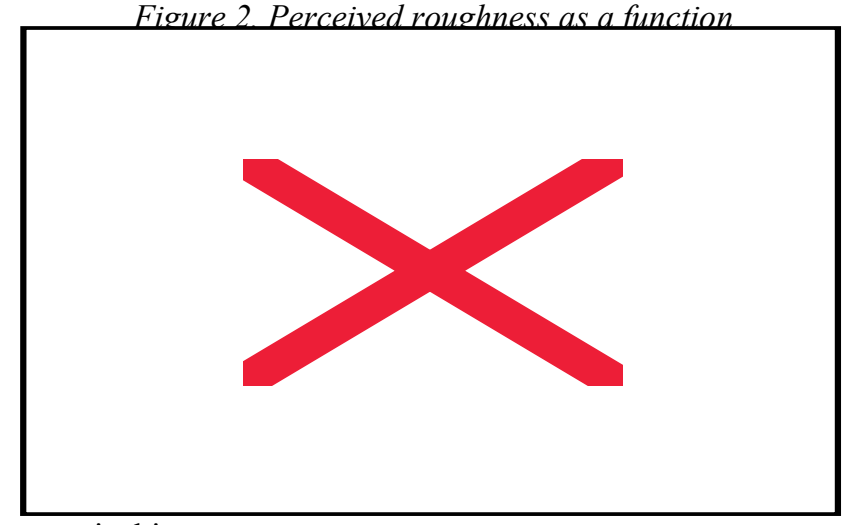

practical importance.

There was hardly any difference between the results when the standard was a real sandpaper and when it was a virtual sandpaper. Any of them can be used in future experiments.

\section{The Perceived Roughness of Virtual Grooved Surfaces}

\subsection{PROBLEM}

The second study of virtual textures investigated the relationship between one particular parameter of a virtual surface and the perception of roughness of the surface. Much of the experimentation on perception of roughness of real surfaces has used surfaces which have equally spaced parallel grooves etched into them. A series of studies by Lederman (1974; 1981; Lederman and Taylor, 1972) found that the most important determinant of perceived roughness is the width of the grooves. Therefore this study investigated the relationship between virtual groove width and the perception of roughness, using virtual materials as close as possible to the real surfaces used in the Lederman studies.

\subsection{METHOD}

\subsubsection{Participants.}

Twenty-two participants took part, 9 were blind and 13 were sighted. Six of the sighted participants were 
female and all the other participants were male. The sighted participants were all university students, from different disciplines. The blind participants were all employed in computer-related jobs or on a computer science course except one, who was a retired audio engineer. Six of the 9 blind participants were either born without sight or lost their sight by the age of 30 months. The other 3 lost their sight between 8 and 26 years of age. The participants ranged in ages from 18 to 65 ; the average age being 32 .

\subsubsection{Haptic display.}

The haptic display used was the Impulse Engine 3000 (see Fig. 3). This force-feedback device was developed by the Immersion Corporation and was used with software written by Andrew Hardwick. The device can display virtual textures and objects which users can feel using a stylus. The stylus is the length and diameter of a thick pen and has 3 degrees of freedom of motion, i.e. it can move in 3 spatial dimensions: forwards and backwards, up and down, and left and right. The system provides force-feedback to users by monitoring the position of their hand and altering the force accordingly (Hardwick, Furner and Rush, 1997). The force is created by three motors which exert resistance against the stylus. This gives users the impression that a texture or object is present.

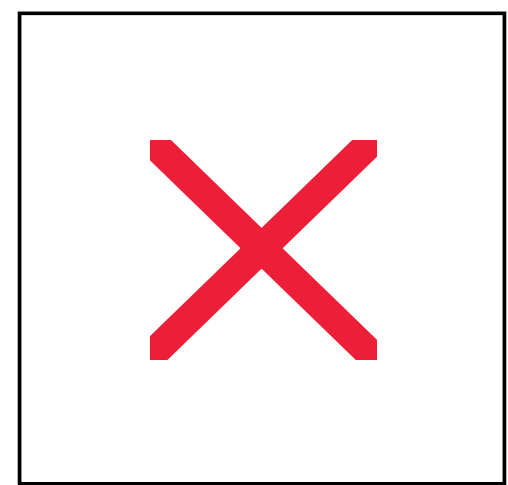

Figure 3. The Impulse Engine $3000^{T M}$

\subsubsection{Stimuli.}

The stimuli comprised virtual textures with varying groove widths. The dimensions of the virtual textures were as close as possible to those used in the investigations of the perception of real textures by Lederman (1974; 1981; Lederman and Taylor, 1972), the only difference being that those real textures involved grooves with a rectangular profile whereas the textures used in the current study involved sinusoidal shaped grooves. This difference was unavoidable, as Lederman

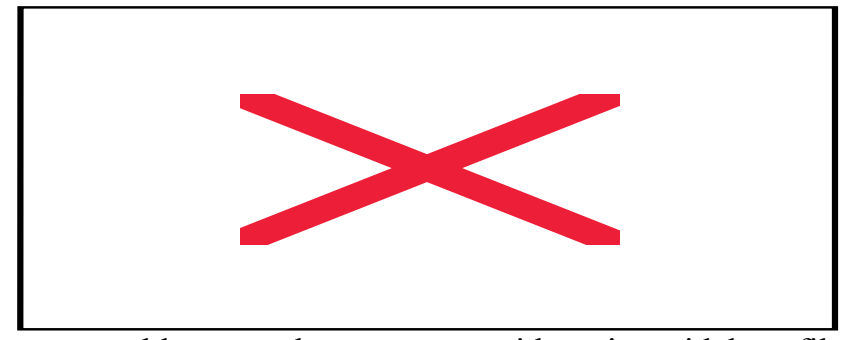

was unable to produce grooves with a sinusoidal profile (although she would have preferred to use such a form) whereas with the Impulse Engine it was not possible to simulate usable rectangular profile textures (preliminary simulations showed that the stylus of the device became "caught" in the corners of the grooves). The widths of the grooves varied from $0.375 \mathrm{~mm}$ to $1.5 \mathrm{~mm}$ in steps of $0.125 \mathrm{~mm}$ and had a fixed amplitude of $0.0625 \mathrm{~mm}$ see Fig. 3). There were no visual representations of the virtual textures.

Figure 4. Dimensions of the sinusoidal grooves

\subsubsection{Procedure.}

The magnitude estimation technique (see section 2.3.4, above) was used to investigate the relationship between the virtual textures and their perception. Participants were presented with a random sequence of 60 textures (the ten textures, each presented six times). For each presentation, they were asked to give a number which represented the texture of the new presentation relative to the standard.

The data were analysed by calculating the power function between virtual texture parameter (i.e. groove width) and perception (i.e. the magnitude estimates) for each participant. Regression analyses were also conducted to determine how much of the variation in the perception of the textures could be accounted for by the variations in the groove width. Regression analyses were conducted for each participant individually and on the massed data which allowed a comparison of the performance of blind and sighted people.

\subsection{RESULTS}

Overall, there was a highly significant relationship between the perception of virtual texture and its simulated physical characteristics $\left(\mathrm{F}_{1,216}=12.09, \mathrm{p}<0.001\right)$. A summary of the analyses for the individual participants is given in Table 1. All nine blind participants also individually showed a significant relationship between perception of virtual texture and its simulated physical 
characteristics. For three of these participants the exponent was positive, meaning that they perceived the narrower grooves to be rougher than the wider grooves. This was in contrast to the other six participants for whom the exponent was negative, meaning that they perceived the wider grooves to be rougher than the narrower grooves. Only five of the thirteen sighted participants showed a significant relationship between perception of virtual texture and its simulated physical characteristics. For all the sighted participants the exponent was negative. The magnitude of the exponents ranged from 0.51 to 0.84 , making them higher than those obtained by Lederman for the closely corresponding real textures.

\begin{tabular}{|c|c|c|c|}
\hline Participant & $\begin{array}{c}\text { Beta } \\
\text { Coefficient }\end{array}$ & $\begin{array}{c}\text { Value of t-test on } \\
\text { beta coefficient }\end{array}$ & $P$ value \\
\hline \multicolumn{4}{|l|}{ Blind } \\
\hline $\mathrm{B} 1$ & -0.457 & 3.433 & 0.001 \\
\hline B2 & -0.306 & 2.295 & 0.0247 \\
\hline B3 & -0.760 & 5.706 & 0.0001 \\
\hline B4 & -0.768 & 5.770 & 0.0001 \\
\hline B5 & 0.747 & 5.611 & 0.0001 \\
\hline B6 & -1.701 & 12.772 & 0.001 \\
\hline B7 & -0.449 & 3.369 & 0.0012 \\
\hline B8 & 0.897 & 6.737 & 0.0001 \\
\hline B9 & 0.841 & 6.314 & 0.0001 \\
\hline \multicolumn{4}{|l|}{ Sighted } \\
\hline $\mathrm{S} 1$ & -0.577 & 1.657 & n.s. \\
\hline S2 & -0.766 & 2.199 & 0.0301 \\
\hline S3 & 0.198 & 0.569 & n.s. \\
\hline S4 & 0.394 & 1.132 & n.s. \\
\hline S5 & -1.601 & 4.598 & 0.001 \\
\hline S6 & 0.331 & 0.952 & n.s. \\
\hline S7 & -1.173 & 3.368 & 0.001 \\
\hline S8 & 0.616 & 1.77 & 0.0796 \\
\hline S9 & -0.750 & 2.153 & 0.0336 \\
\hline S10 & -0.157 & 0.451 & n.s. \\
\hline S11 & -1.511 & 4.339 & 0.0001 \\
\hline S12 & 0.205 & 0.589 & n.s. \\
\hline S13 & 0.079 & 0.228 & n.s. \\
\hline
\end{tabular}

Table 1. Summary of analyses of relationship between virtual texture and its perception

\subsection{DISCUSSION}

The results from this study showed that all the blind participants perceived a meaningful relationship between groove width and roughness, but only a minority of the sighted participants perceived this relationship. This means that virtual textures of the range of parameters investigated would not be suitable for creating distinguishable textures in virtual environments, unless they were only intended for blind users. This view is further reinforced by the finding that there were differences in the way participants perceived the relationship between the virtual texture parameter and roughness, with most participants perceiving the wider groove widths to be more rough than the narrower groove widths, although some participants perceived the narrower grooves to be rougher.

\section{Identification of 3D Virtual Geometric Forms}

\subsection{PROBLEM}

If any method of rendering virtual objects is to be successful, it is important that their $3 \mathrm{D}$ form can be identified by the observers. The experimental problem in this part of the investigation was to get an initial idea about how well observers can identify differently sized 3D geometric forms rendered by a PHANToM $1.5 \mathrm{~A}$ and explored with a stylus.

\subsection{METHOD}

\subsubsection{Participants.}

Ten paid sighted university students (seven women and three men) with a mean age of 22 years ( $\mathrm{SD}=2$ years) took part. All used their right hand for exploration.

\subsubsection{Stimuli}

4.2.2.1 Rendering of $3 D$ Geometric Forms. The software, called ENCHANTER, for rendering the experimental forms was developed by Fänger and König (1998) in co-operation with the author. It is based on the software GHOST ${ }^{\text {TM }}$ SDK and provides the user with possibilities of easy rendering of 3D geometric forms with several different properties for presentation in experiments.

4.2.2.2 3D Geometric Forms Studied. Four 3D forms were used (cube, sphere, cylinder and cone) in three different sizes, maximum in all three dimensions being 10, 50 and $100 \mathrm{~mm}$. In order for the 3D forms to be easily localised they were positioned in the middle of a cubical enclosure with dimensions twice those of each 3D form, and for the $3 \mathrm{D}$ forms and their enclosure to be certainly discriminated the 3D form surface had no static friction while the inside surfaces of the enclosure had a high such friction.

\subsubsection{Procedure}

The participants were informed about the PHANToM and the safety aspects and they were allowed to acquaint themselves with the device. The 3D geometric forms to be used were explained for the participants with the help of drawings. There were no restrictions on how to use the stylus, but the participants usually kept the stylus similar to a pen. The head protective device and eye cover were applied, and the experiment proper began. (As the PHANToM made very little noise during the exploration of these $3 \mathrm{D}$ forms the sound was not masked.) 
The participants were presented with the $3 \mathrm{D}$ virtual forms one by one and asked to identify their form as fast and accurately as possible (with equal emphasis on both aspects). Maximum $1 \mathrm{~min}$ was allowed per 3D form. The verbal responses and the time used for each $3 \mathrm{D}$ form were recorded.

\subsubsection{Design .}

All participants took part in all conditions. Each participant was presented three blocks with the 12 3D forms in random order, thus altogether 36 3D forms.

\subsection{RESULTS}

The percentages of correct responses and mean explorations times, both parameters over all participants, are presented in Figures 5 and 6 . The percent of correct responses is highly above chance level $(25 \%)$. In fact, the sphere was correctly identified every time, even in its smallest size. A majority (52\%) of the mistakes for the other 3D forms were made during the first replication. If only the second and third replication had been included the percent correct responses would have been $95 \%$ over all 3D forms and sizes. This demonstrates a quite rapid learning to identify the $3 \mathrm{D}$ forms when the identification is not perfect from the start. The size threshold for correct identification is apparently smaller than $10 \mathrm{~mm}$.

Figure 6 indicates differences in exploration time between the $3 \mathrm{D}$ form and sizes. For all the $3 \mathrm{D}$ forms the time for the $10 \mathrm{~mm}$ size in longer than for the larger sizes. The sphere is not only always correctly identified, but also the time to explore it is shortest for all sizes.

\subsection{DISCUSSION}

The results show clearly that the PHANToM can provide the blindfolded sighted participants in this experiment with useful information without vision under the conditions of the experiment. It is of interest to compare this result with the result in a similar experiment with visually impaired participants (Jansson, Fänger, König \& Billberger, 1998). Of the ten participants six had about the same performance as the sighted participants in this experiment. The remaining four had difficulties in performing the task, resulting in many mistakes and unfinished tasks. In a follow-up study the low-performing participants were tested anew after training in finding and exploring the virtual objects. The training raised the results considerably. This indicates that visually impaired observers may have difficulty in using the force-feedback device initially but that training may at least partially solve the problems.

A note should be made about potential effects of sound not being masked. It was assumed before the experiment that the sound could not be used for identification of the 3D forms. Spontaneous comments by some participants indicated, however, that it may have contributed. It cannot be excluded that it was used by some participants for the detection of edges. If this was the case, it is not a problem from an applied point of view, as the auditory information is available also for visually impaired people (if they have no hearing loss), but for future experiments about haptics alone it is recommended that sound is always masked.

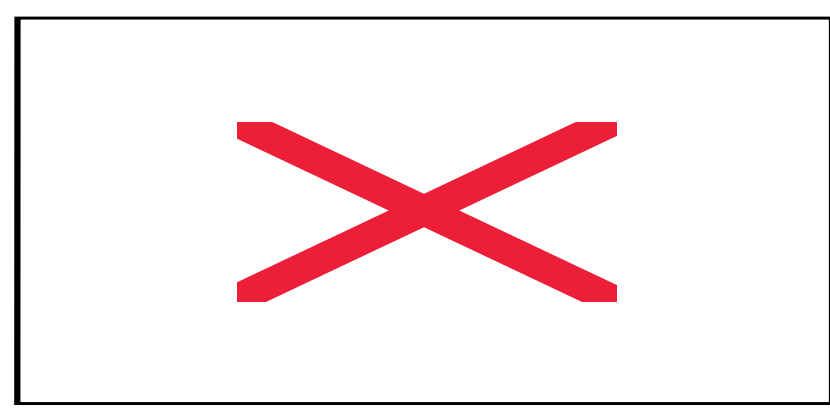

Figure 5. Percent correct responses for each of the four $3 D$ forms and three sizes.

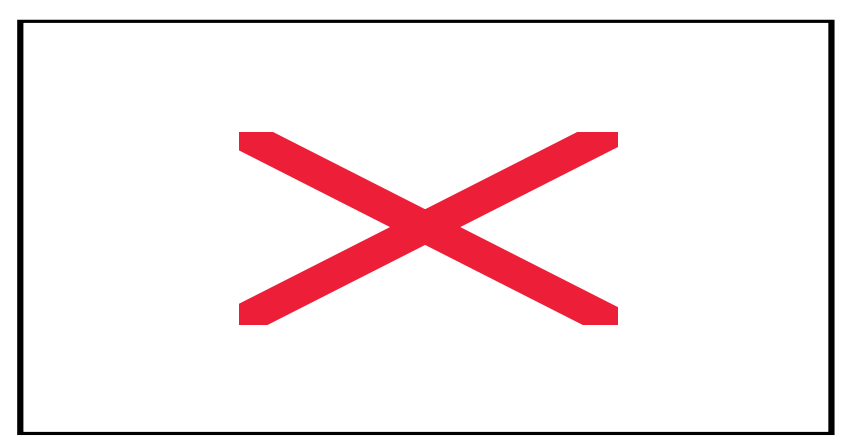

Figure 6. Mean exploration time (sec.) as a function of $3 \mathrm{D}$ form and size $(\mathrm{mm})$.

\section{The Recognition of Virtual Objects}

\subsection{PROBLEM}

The second study with the Impulse Engine 3000 investigated whether blind and sighted people could perceive the size of a range of virtual objects, including the size of virtual objects with planes at unusual angles (sheared cubes). The Impulse Engine 3000 allows virtual objects to be explored from both inside and outside the object, so for some of the virtual objects used, exploration was from both inside and outside the object to investigate any differences this factor produced.

\subsection{METHOD}

\subsubsection{Design}

Since this was an initial exploratory study, a full factorial design was not used. Each type of virtual object 
was presented three times, with a range of different sizes and angles of shear.

\subsubsection{Participants}

The same participants who undertook the first study with the Impulse Engine 3000 (see section 3.2.1, above).

\subsubsection{Stimuli}

The virtual objects used were: cubes (inside and outside exploration), spheres (inside and outside exploration), and sheared cubes (inside exploration only). Three sizes of each type of virtual object were presented: cubes with edges ranging from $1.0 \mathrm{~cm}$ to $2.5 \mathrm{~cm}$ (see Table 2), spheres with diameters ranging from $1.5 \mathrm{~cm}$ to $2.5 \mathrm{~cm}$. The amount of shear between 18 degrees and 64 degrees.

\subsubsection{Procedure}

Each type of virtual object was presented three times, with a range of different sizes and angles of shear. A multiple choice matching response method was used. Participants were asked to explore an object and then choose from a set of four objects of varying size the one they thought they had felt. Sighted participants were shown scale drawings and blind participants were shown scale tactile 2D representations.

\subsection{RESULTS}

Since a full factorial design was not employed, a series of analyses of variance were used to analyse different components of the data. Mean perceived sizes and angles for the various objects used are shown in Table 2 and 3. No significant difference was found between the perceptions of sighted and blind participants, except that the sighted participants judged the sheared cubes more accurately than the blind participants. Both groups were significantly more accurate in their perception of larger objects than of smaller objects. For example, the $1.0 \mathrm{~cm}$ edge cube was perceived on average to have a $1.8 \mathrm{~cm}$ edge when explored from the

\begin{tabular}{|c|c|c|c|c|c|}
\hline $\begin{array}{c}\text { Object } \\
\text { Type }\end{array}$ & $\begin{array}{c}\text { Actual } \\
\text { Size } \\
(\mathbf{c m})\end{array}$ & \multicolumn{2}{|c|}{$\begin{array}{c}\text { Perceived Size } \\
\text { Inside exploration }\end{array}$} & \multicolumn{2}{|c|}{$\begin{array}{c}\text { Perceived Size } \\
\text { Outside exploration }\end{array}$} \\
\cline { 3 - 6 } & & $\begin{array}{c}\text { Mean and } \\
\text { standard } \\
\text { deviation } \\
\text { (cm) }\end{array}$ & $\begin{array}{c}\text { Percentage } \\
\text { Over/Under } \\
\text { estimation }\end{array}$ & $\begin{array}{c}\text { Mean and } \\
\text { standard } \\
\text { deviation } \\
\text { (cm) }\end{array}$ & $\begin{array}{c}\text { Percentage } \\
\text { Over/Under } \\
\text { estimation }\end{array}$ \\
\hline \hline Cube & 1.0 & $1.8(0.40)$ & $+80 \%$ & $\begin{array}{c}\text { See Note } 1 . \\
1.6(0.50)\end{array}$ & $+7 \%$ \\
& 1.5 & $1.7(0.30)$ & +13 & $2.0(0.50)$ & 0 \\
& 2.0 & $2.4(0.20)$ & +20 & $2.4(0.20)$ & -7 \\
\hline Sphere & 2.5 & See Note 2. & - & $1.2(0.40)$ & -20 \\
& 1.5 & $2.1(0.10)$ & +27 & $1.8(0.50)$ & -10 \\
& 2.0 & $2.3(0.10)$ & +15 & $2.3(0.30)$ & -8 \\
\hline
\end{tabular}

Notes:

1. Preliminary investigations showed that a $1.0 \mathrm{~cm}$ edge cube was too difficult for participants to find in the outside exploration condition, so that condition was dropped from the study.

2. Preliminary investigations showed that a $2.5 \mathrm{~cm}$ edge cube was too big to the virtual space available, so that condition was dropped from the study.

Table 2. Mean perceived size of virtual objects with percentage over- and under-estimation (data from blind and sighted participants combined).

\begin{tabular}{|c|c|c|c|}
\hline Cube & $\begin{array}{c}\text { Actual } \\
\text { Angle } \\
\text { (degrees) }\end{array}$ & $\begin{array}{c}\text { Perceived Angle } \\
\text { Mean and } \\
\text { standard deviation } \\
\text { (degrees) }\end{array}$ & $\begin{array}{c}\text { Percentage } \\
\text { Over/Under } \\
\text { estimation }\end{array}$ \\
\hline \hline & 18 & $20.0(11.0)$ & $+11 \%$ \\
& 41 & $37.0(11.0)$ & -10 \\
$-8.0(9.7)$ & 8 \\
\hline
\end{tabular}

Table 3. Mean perceived angle of sheared for virtual cubes with percentage over-and under-estimation (data from blind and sighted participants combined) 
inside, an overestimate of $80 \%$, whereas the $2.0 \mathrm{~cm}$ cube was perceived on average to have a $2.4 \mathrm{~cm}$ edge, an overestimate of only $20 \%$. The size of the objects explored from the inside tended to be overestimated, the mean overestimation across all sizes of cubes and spheres being $25.8 \%$. However, the size of objects explored from the outside tended to be underestimated, with a corresponding mean underestimation of $6.3 \%$.

\subsection{DISCUSSION}

The results on the perception of the sizes and angles of virtual objects show some interesting effects which warrant further investigation. Estimation of larger objects was more accurate than estimation of smaller objects. In addition, exploration from the inside tended to result in the overestimation of the size of virtual objects, whereas exploration from the outside tended to result in underestimation.

The way in which a user of the Impulse Engine $3000^{\mathrm{TM}}$ can explore virtual objects differs from the way in which real objects are felt in several ways. An example is that the device currently requires the user to feel textures and objects with the stylus. This is not a particularly intuitive way of interacting with objects and several participants said they would rather use their hands because they are more used to feeling their environment in this way. A further example is that if the user pushes hard enough they can have the sensation of pushing through the surface of an object. This is because the Impulse Engine 3000 motors are capable of withstanding only 8 Newtons (approximately $2 \mathrm{lbf}$ ) of force from the user.

Hardwick, Rush, Furner \& Seton (1996) observed an interesting phenomenon associated with the Impulse Engine 3000 , whereby people differ in terms of where they think the virtual space is located in real space. Some people have a mental image of the virtual space being outside the device, so that virtual objects are felt to be near the hand and are touched by the end of the stylus that they hold (Figure 7a). In contrast, others imagine the virtual space to be within the device, so that virtual objects are touched by the other end of the stylus (Figure $7 b$ ).

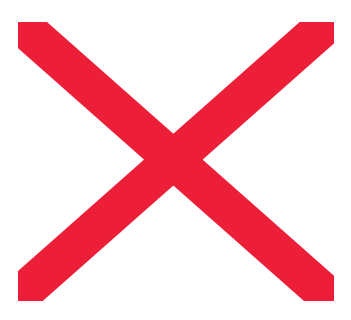

\section{Figure 7. Representation of different mental models of the location of a virtual object: \\ (a) outside the device. (b) inside the device}

This phenomenon was explored further during the current studies asking each participant where in real space they thought the object was located, and to point to this location. Data on this phenomenon were collected from 19 of the participants. 14 (74\%) imagined the objects to be located inside the device, $4(21 \%)$ imagined the objects to be outside, and $1(5 \%)$ imagined them to be half-way. Three $(33 \%)$ of the blind participants imagined the objects to be located outside of the device, compared to only $1(8 \%)$ of the sighted participants. Of the participants who imagined the objects to be outside the device, 3 were blind and 1 was sighted. Therefore, this phenomenon may be more prevalent amongst blind people than sighted people, but is worthy of further investigation.

\section{Conclusions}

Both the haptic devices studied offer exploration of their virtual worlds via a stylus with only one point of contact at each time. The information obtained with them is thus based on movement information to the muscles, tendons and joints and not also on spatially distributed cutaneous information which is the case in natural haptics. In spite of this limitation, virtual textures and 3D objects rendered by these devices can be effectively perceived by both blind and blindfolded sighted observers. Further studies of the effectiveness of these devices for visually impaired people are highly motivated

To this positive conclusion some comments of caution must be added. First, the differences between blind and sighted observers, observed both within the present experiments and between experiments here and related experiments deserves further attention. Second, the differences between rendered and perceived properties obtained in one of the present experiments ought to be more investigated. Third, the textures and objects studied were quite simple. The lack of simultaneous distributed spatial information may have greater effects when the textures and 3D objects are more complex.

\section{Acknowledgements}

We would like to thank all the people who participated in these studies. The studies conducted in Sweden were made possible by grants from the Swedish Council for Research in Humanities and Social Sciences and from the Swedish Transport and Communications Research Board. The Swedish authors are indebted to Donald Green, Massachusetts Institute of Technology, Cambridge, MA, for making his computer software PALPATE available for this study, and to Lars-Erik Larsson for technical assistance. Chetz Colwell is a $\mathrm{PhD}$ candidate supported by the Economic and Social Research Council, U.K. and M.A. Systems and Control Ltd, U.K. 


\section{REFERENCES}

G C Burdea (1996), Force and touch feedback for virtual reality, Wiley, New York.

P K Edman (1992), Tactile graphics, American Foundation for the Blind, New York.

J Fänger \& H König (1998), Entwicklung einer Modellierungs- und Experimentierumgebung für eine Kraftrückskopplungsgerät (Development of a form production and experiment environment for a force feedback device), Praktikumsdokumentation, Institute for Simulation and Graphics, Magdeburg University, Germany.

J J Gibson (1962), Observations on active touch, Psychological Review, 69, pp. 477-491.

D F Green \& J K Salisbury (1997), Texture sensing and simulation using the PHANToM: Towards remote sensing of soil properties, In Proceedings of the Second PHANToM Users Group Workshop (J K Salisbury \& N A Srinivasan, Eds), A.I. Technical Report No. 1617 and R.L.E. Technical Report No. 618, Massachusetts Institute of Technology, Cambridge, MA.

A Hardwick, J Rush, S Furner, \& J Seton, (1996), Feeling it as well as seeing it - haptic display within gestural HCI for multimedia telematics services, In Progress in Gestural Interaction (Proceedings of Gesture Workshop '96) (P A Harling \& A D N Edwards Eds), SpringerVerlag, pp. 105-116.

A Hardwick, S Furner, \& J Rush, (1997) Tactile access for blind people to virtual reality on the World Wide Web. IEE Digest No. 96/012 (Colloquium on Developments in Tactile Displays), 9/1-9/3.

M A Heller (1982), Visual and tactual texture perception: Intersensory cooperation, Perception \& Psychophysics, 31, pp. 339-344.

M A Heller, J A Calcaterra, L A Tyler \& L L Burson (1996) Production and interpretation of perspective drawings by blind and sighted people, Perception, 25, pp. 321334.

E Holmes, B Hughes \& G Jansson (1998), Haptic perception of texture gradients, Perception, 27, pp. 9931008 .

B Hughes \& G Jansson (1994), Texture perception via active touch, Human Movement Science, 13, pp. 301333.

G Jansson (1988). What are the problems with tactual pictures, and what can we do to solve them? In ManMachine Interfaces, Graphics and Practical Applications (C W M Magne'e, F J M Vlaskamp, M Soede, \& G Butcher, Eds.), Royal National Institute for the Blind, London, pp. 18-24.

G Jansson (1998). Haptic perception of outline 2D shape: The contributions of information via the skin, the joints and the muscles. In Advances in perception-action coupling (B Bril, A Ledebt, G Dietrich \& A RobyBrami, Eds), Éditions EDK, Paris, pp. 25-30.
G Jansson, J Fänger, H König \& K. Billberger (1998), Visually impaired persons' use of the PHANToM for information about texture and 3D form of virtual objects. In Preprints of the Third PHANToM User's Group Workshop. Cambridge, MA: Massachusetts Institute of Technology, AI Lab, RLE and ME.

D Katz (1989), The world of touch (L E Krueger, Translator), Erlbaum, Hillsdale, NJ. Original work published 1925.

J M Kennedy (1993), Drawing and the Blind, Yale University Press, New Haven, CT.

R L Klatzky \& S J Lederman (in press), Tactile roughness perception with a rigid link interposed between skin and surface, Perception \& Psychophysics.

G D Lamb (1983), Tactile discrimination of textured surfaces: Psychophysical performance measurements in humans, Journal of Physiology (London), 338, pp. 551565.

S J Lederman (1974), Tactile roughness of grooved surfaces: the touching process and effects of macro- and microsurface structure, Perception \& Psychophysics, 16(2), pp. 385-395.

S J Lederman (1981), The perception of surface roughness by active and passive touch, Bulletin of the Psychonomic Society, 18, pp. 253-255.

S J Lederman (1983), Tactile roughness perception: Spatial and temporal determinants, Canadian Journal of Psychology, 37, pp. 498-511.

S J Lederman \& R L Klatzky (in press), Sensing and displaying spatially distributed fingertip forces in haptic interfaces for teleoperater and virtual environment systems, Presence.

S J Lederman and M M Taylor (1972) Fingertip force, surface geometry, and the perception of roughness by active touch, Perception and Psychophysics, 12(5), pp. 401-408.

J M Loomis \& S J Lederman (1986), Tactual perception. In Handbook of perception and human performance (K R Boff, L Kaufman \& J P Thomas,.Eds.) Wiley, New York, pp. $31-1-41$.

G Révész (1950), Psychology and Art of the Blind, Longmans, Green and Co, London.

J G Snodgrass, G Levy-Berger \& M Haydon (1985), Human experimental psychology. Oxford University Press, New York.

F Vega-Bermudez, K O Johnson \& S S Hsiao (1991), Human tactile pattern recognition: Active versus passive touch, velocity effects, and patterns of confusion, Journal of Neurophysiology, 65, pp. 531-546.

\section{BIOGRAPHIES}

Gunnar Jansson is retired Associate Professor at Department of Psychology, Uppsala University, Sweden. His research concerns both basic and applied perception problems. Most recently he has been engaged in problems of haptics, especially as used by visually impaired people. 
The work includes problems of reading 2D tactile pictures, as well as displays rendering virtual 3D objects.

\section{Contact information:}

Gunnar Jansson

Department of Psychology

Uppsala University

Box 1225, SE-751 42 Uppsala, SWEDEN

Email: gunnar.jansson@psyk.uu.se

Biographies of the other authors, as well as photos, are included on the CDROM. 